\title{
Effect of Protein Kinase $C$ and Protein Kinase A Inhibitors on Contraction of Isolated Femoral Arteries of SHR and Wistar Rats
}

\author{
M. S. BAL ${ }^{1,2}$, L. PAULIS ${ }^{2,3,4}$, J. ZICHA ${ }^{2}$, J. KUNES $^{2}$ \\ ${ }^{1}$ University of Texas Health Science Center at San Antonio, San Antonio, Texas, USA, ${ }^{2}$ Institute of \\ Physiology AS CR, Prague, Czech Republic, ${ }^{3}$ Institute of Pathophysiology, School of Medicine, \\ Comenius University, Bratislava, and Institute of Normal and Pathological Physiology, Slovak \\ Academy of Sciences, Bratislava, Slovak Republic, ${ }^{4}$ Center for Cardiovascular Research, Charité, \\ Berlin, Germany
}

Received July 8, 2008

Accepted November 20, 2008

On-line December 17, 2008

\section{Summary}

Alterations of calcium handling and other second messenger cascades including protein kinase $\mathrm{C}$ (PKC) and $\mathrm{A}$ (PKA) were suggested to be responsible for abnormal vascular function in spontaneously hypertensive rats (SHR). However, the relative contribution of these pathways to vasoconstriction is still not completely understood. We investigated the effect of Ro 31-8220 (PKC inhibitor) and H89 (PKA inhibitor) on vasoconstriction induced by $120 \mathrm{mM} \mathrm{KCl}$ or by addition of $10 \mu \mathrm{M}$ noradrenaline (NA) in isolated femoral arteries of control Wistar rats and SHR. Moreover, we investigated these responses in the presence and absence of $\mathrm{Ca}^{2+}$ ions in the incubation medium in order to assess the role of calcium influx in these contractions. We observed that while the vasoconstriction in the presence of calcium was not different between Wistar and SHR, the difference between constriction elicited by NA addition in the absence and presence of external calcium was larger in SHR. The inhibition of PKC had no effect on constrictions in SHR, but diminished constrictions in Wistar rats. PKA inhibition slightly enhanced constrictions in Wistar rats, but reduced them in the presence of calcium in SHR. We conclude that vasoconstriction elicited by adrenergic stimulation is more dependent on extracellular calcium influx in SHR compared to Wistar rats. Moreover, the activation of PKA contributes to this calcium-dependent vasoconstriction in SHR but not in Wistar. On the other hand, PKC activation seems to play a less important role in vasoconstriction in SHR than in Wistar rats.

\section{Key words}

Protein kinase C • Protein kinase A • Femoral artery • Calcium • Myograph

\section{Corresponding author}

L. Paulis, Charité Universitätsmedizin, Center for Cardiovascular Research, Hessische Strasse 3-4, 10115 Berlin, Germany. Fax: +4930450525002. E-mail: ludo@lfuk.sk

\section{Introduction}

Spontaneously hypertensive rats (SHR) represent an attractive model of essential hypertension. Augmented vasoconstrictor ability of arteries isolated from SHR was proposed to be involved in this type of hypertension. Several studies have reported abnormalities of vascular smooth muscle in SHR. These include disturbed cell $\mathrm{Ca}^{2+}$ handling (Hermsmeyer et al. 1989, Martens et al. 1998, Lompre 1999, Cox 2002) probably linked to abnormal properties of L-type voltage-dependent $\mathrm{Ca}^{2+}$ channels (VDCC) in SHR (Hermsmeyer et al. 1989, Matsuda et al. 1997), which display higher L-type $\mathrm{Ca}^{2+}$ current density due to a more frequent opening of the channels (Ohya et al. 1998). Available studies also suggest that there may be an increased number of L-type $\mathrm{Ca}^{2+}$ channel pores (Pratt et al. 2002) or increased $\mathrm{Ca}^{2+}$ stores (Goldberg et al. 1977, Miquel et al. 2005). Furthermore, the $\mathrm{Ca}^{2+}$-sensitivity of vascular smooth muscle could be modulated by protein kinase C (Kitazawa et al. 2000) or protein kinase A (Wooldridge et al. 2004). PKC was proposed to be upregulated (Kanashiro et al. 2001) and PKA less active in SHR (Alemany et al. 2006).

In vascular smooth muscle, PKC and PKA are 
activated by noradrenaline through stimulation of $\mathrm{G}_{\mathrm{q}}$ and $\mathrm{G}_{\mathrm{s}}$ proteins, respectively (Nishizuka 1988, Somlyo et al. 1988) or to lesser extent by membrane depolarization (Takuwa and Rasmussen 1987, Ko et al. 2008). The role of PKC in the regulation of smooth muscle was suggested by the finding that tumor-promoting phorbol esters, which specifically activate PKC, induce sustained contractions in smooth muscles (Castagna et al. 1982, Rasmussen et al. 1987). The second messenger adenosine 3', 5'-cyclic monophosphate (cAMP) was shown to mediate its effects through PKA activation leading to relaxation of smooth muscle (Somlyo et al. 1994) mainly by $\mathrm{Ca}^{2+}$-dependent or -independent effects (Somlyo et al. 2003, Nishimura et al. 1989).

The aim of our study was to evaluate the relative contribution of calcium influx to vascular constriction induced by $\mathrm{KCl}$ or adrenergic stimulation in SHR. Furthermore, we intended to elucidate the role of PKC and PKA recruitment in this vasoconstriction.

\section{Methods}

Male 3-month-old SHR and Wistar rats were sacrificed by ether overdosage. Femoral arteries were isolated, cleaned, and cut into segments of equal length. Attention was paid to preserve the endothelium of the arteries. The segments were subsequently mounted on standard Mulvany-wire myograph (610M; Danish Myo Technology, Aarhus, Denmark) filled with modified Krebs-Henseleit solution (KHS, $\mathrm{pH}$ 7.4) of the following composition (in $\mathrm{mM}$ ): $\mathrm{NaCl} 120, \mathrm{NaHCO}_{3} 25$, glucose 11.1, $\mathrm{CaCl}_{2}$ 1.6, $\mathrm{KCl} 4.7, \mathrm{KH}_{2} \mathrm{PO}_{4} 1.2, \mathrm{MgSO}_{4} 1.2$, and oxygenated with $95 \% \mathrm{O}_{2}: 5 \% \mathrm{CO}_{2}$. The rings were first equilibrated for $1 \mathrm{~h}$ at $37{ }^{\circ} \mathrm{C}$ and then constricted with 120 $\mathrm{mM} \mathrm{KCl}$ followed by addition of $10 \mu \mathrm{M}$ noradrenaline (NA). After reaching a steady-state, the rings were washed with KHS containing nominally $0 \mathrm{mM} \mathrm{CaCl}{ }_{2}$, (KHS 0 $\mathrm{Ca}^{2+}$ ) and once the resting tension was restored, the protocol was repeated in KHS $0 \mathrm{Ca}^{2+}$ solution (Fig. 1). In fresh arteries, the same protocol was implemented after a 30 min preincubation with PKC (Ro 31-8220) or PKA (H89 ) inhibitor (both Biaffin, Germany). H-89 was dissolved as a stock solution of $1 \mathrm{mM}$ in $100 \%$ dimethyl sulfoxide, the final concentration of both inhibitors used was $1 \mu \mathrm{M}$ (Budzyn et al. 2006). All other drugs were dissolved and diluted in deionized water. During the experiment, the generated force was recorded and wall tension was automatically calculated by the myograph system. Data are expressed as mean \pm S.E.M., $\mathrm{P}<0.05$ (one-way, two-tailed, unpaired Student's t-test) was considered significant. All procedures and experimental protocols were approved by the Ethical Committee of the Institute of Physiology AS CR, and conform to the European Convention on Animal Protection and Guidelines on Research Animal Use.

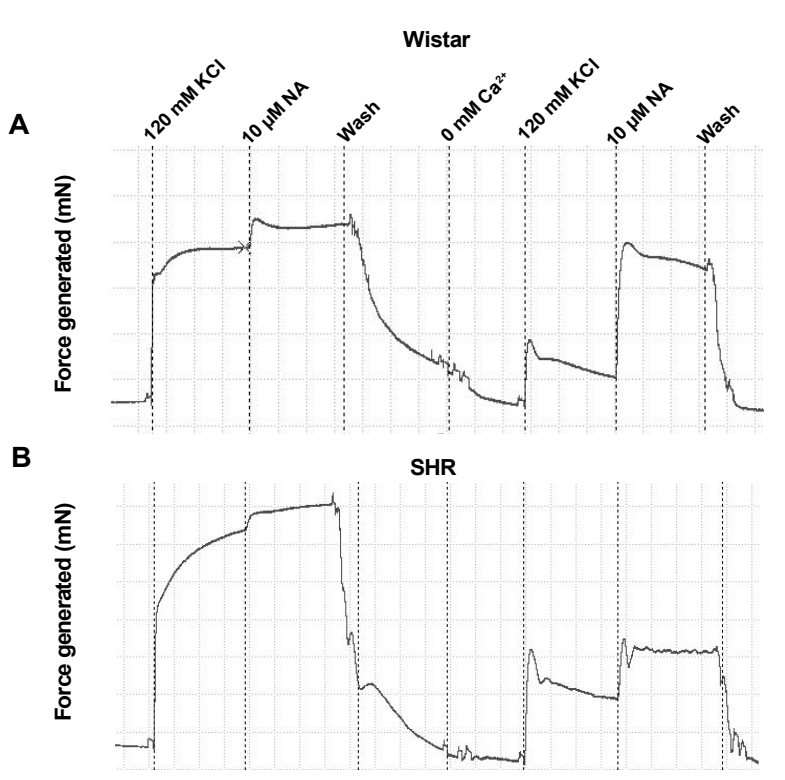

Fig. 1. Original records of force generated by femoral artery of control (Wistar, upper panel) and spontaneously hypertensive rats (SHR, lower panel) stimulated with $120 \mathrm{mM} \mathrm{KCl}$ (6 min) followed by addition of $10 \mu \mathrm{M}$ noradrenaline (NA) in KrebsHenseleit solution (KHS) containing $1.6 \mathrm{mM} \mathrm{Ca}^{2+}$ and in KHS nominally free of $\mathrm{Ca}^{2+}$ Horizontal bar represents $5 \mathrm{~min}$.

\section{Results}

\section{Basic parameters of the isolated arteries}

The normalized inner diameter under tension corresponding to pressure of $100 \mathrm{~mm} \mathrm{Hg}$ was 953.4 $24.3 \mu \mathrm{m}$ in Wistar controls vs. 909.5 $\pm 21.5 \mu \mathrm{m}$ in SHR (non-significant). The segment length was not different between Wistar and SHR vessels $(2.16 \pm 0.07 \mathrm{~mm}$ in Wistar vs. 2.19 $\pm 0.06 \mathrm{~mm}$ in SHR).

\section{Constriction induced by $\mathrm{KCl}$ and $\mathrm{KCl}+$ noradrenaline}

The vasoconstriction elicited by $\mathrm{KCl}$ or $\mathrm{KCl}+$ NA in KHS $1.6 \mathrm{Ca}^{2+}$ or by $\mathrm{KCl}$ in $\mathrm{KHS} 0 \mathrm{Ca}^{2+}$ was not different between control rats and SHR. The vasoconstriction elicited by $\mathrm{KCl}+\mathrm{NA}$ in $\mathrm{KHS} 0 \mathrm{Ca}^{2+}$ was lower in SHR compared to controls $(\mathrm{P}<0.05)$ (Fig. 2).

Effect of PKC inhibition on constriction induced by $\mathrm{KCl}$ or $\mathrm{KCl}+$ noradrenaline

When PKC inhibitor was present in KHS 
A

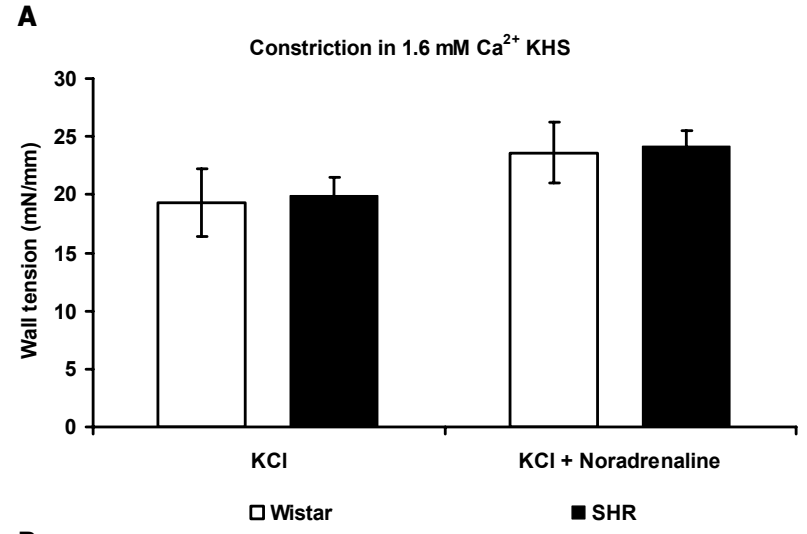

B

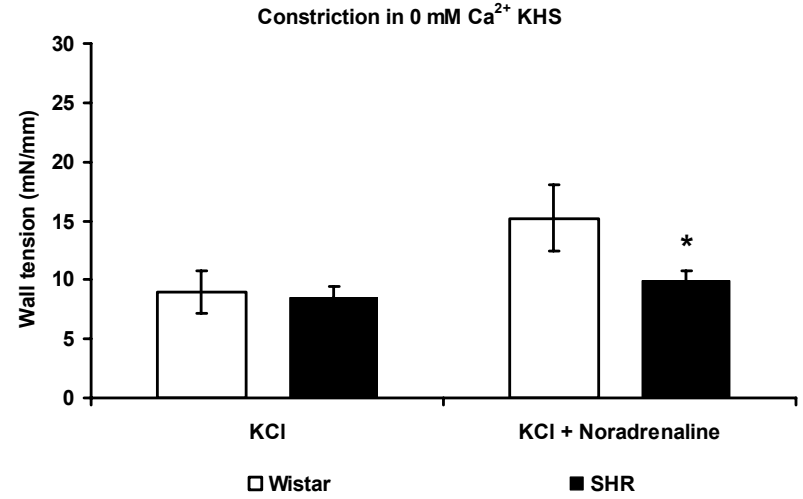

Fig. 2. Vasoconstriction obtained after stimulation of femoral artery of control (Wistar) and spontaneously hypertensive rats (SHR) stimulated with $120 \mathrm{mM} \mathrm{KCl}$ and $\mathrm{KCl}+10 \mu \mathrm{M}$ noradrenaline (NA) in Krebs-Henseleit solution (KHS) containing $1.6 \mathrm{mM} \mathrm{Ca}^{2+}(\mathbf{A})$ and in KHS nominally free of $\mathrm{Ca}^{2+}(\mathbf{B}) . * P<0.05$ vs. controls.

1.6 $\mathrm{Ca}^{2+}$ medium, the constrictions of arteries isolated from control Wistar rats were decreased compared to constrictions seen in its absence $(\mathrm{P}<0.05)$. The incubation with PKC inhibitor did not affect constrictions of arteries from SHR and therefore the constriction elicited by $\mathrm{KCl}+$ NA in SHR became higher compared to Wistar controls $(\mathrm{P}<0.05)$ (Fig. 3A).

The presence of PKC inhibitor in KHS $0 \mathrm{Ca}^{2+}$ medium decreased the constrictions induced by $\mathrm{KCl}+\mathrm{NA}$ in arteries isolated from Wistar rats compared to constrictions observed in its absence $(\mathrm{P}<0.05)$. The incubation with $\mathrm{PKC}$ inhibitor did not affect constrictions of arteries from SHR and therefore constriction elicited by $\mathrm{KCl}+\mathrm{NA}$ in SHR was not different from respective controls (Fig. 3B).

Effect of PKA inhibition on constriction induced by $\mathrm{KCl}$ or $\mathrm{KCl}+$ noradrenaline

In the presence of PKA inhibitor in KHS $1.6 \mathrm{Ca}^{2+}$ medium the constrictions of arteries isolated from control Wistar rats were non-significantly higher

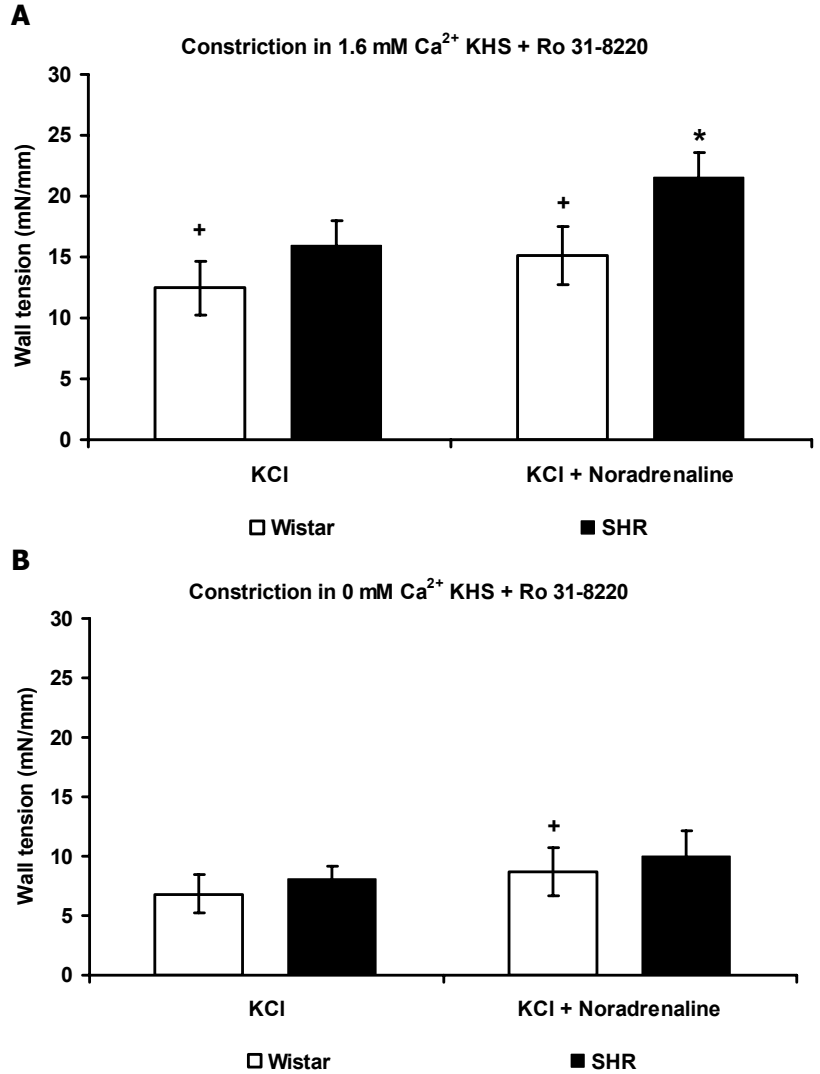

Fig. 3. Vasoconstriction in the presence of protein kinase $C$ inhibitor Ro-31-8220 obtained after stimulation of femoral artery of control (Wistar) and spontaneously hypertensive rats (SHR) stimulated with $120 \mathrm{mM} \mathrm{KCl}$ and $\mathrm{KCl}+10 \mu \mathrm{M}$ noradrenaline (NA) in Krebs-Henseleit solution (KHS) containing $1.6 \mathrm{mM} \mathrm{Ca}^{2+}$ (A) and in KHS nominally free of $\mathrm{Ca}^{2+}$ (B). $* p<0.05$ VS. controls, ${ }^{+} P<0.05$ vs. respective group in the absence of the inhibitor.

compared to those recorded in its absence. The incubation with PKA inhibitor reduced constrictions of arteries from SHR $(\mathrm{P}<0.05)$ and therefore constriction in SHR became lower compared to controls $(\mathrm{P}<0.05)$ (Fig. 4A).

In the presence of PKA inhibitor in KHS $0 \mathrm{Ca}^{2+}$ medium the constrictions of arteries isolated from control rats were slightly but non-significantly higher compared to the conditions when PKA inhibitor was absent. The incubation with PKA inhibitor tended to reduce the constrictions of arteries from SHR, but the constriction in SHR was lower compared to Wistar controls $(\mathrm{P}<0.05)$ (Fig. 4A).

\section{Discussion}

In our in vitro experiments on isolated femoral arteries we observed that the constriction elicited by $\mathrm{KCl}$ or $\mathrm{KCl}+$ noradrenaline (NA) in Krebs-Henseleit solution containing $1.6 \mathrm{mM} \mathrm{Ca}^{2+}$ (KHS $1.6 \mathrm{Ca}^{2+}$ ) or by $\mathrm{KCl}$ in the nominally calcium-free KHS (KHS $0 \quad \mathrm{Ca}^{2+}$ ) was not 
A

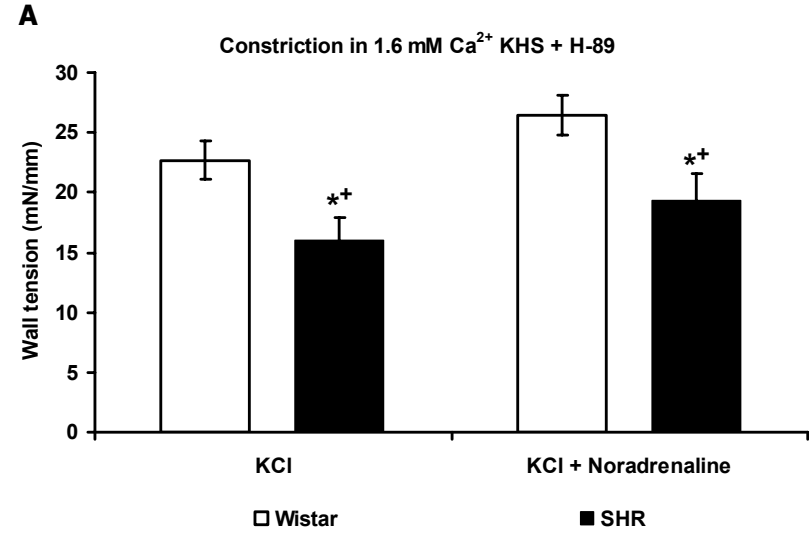

B

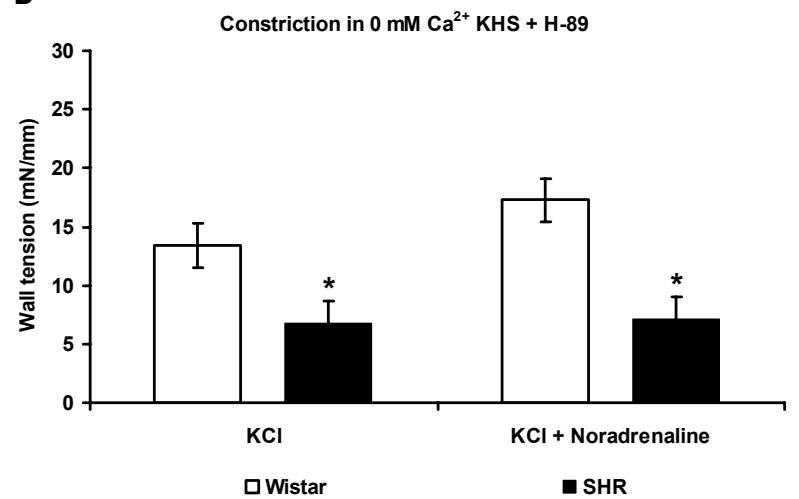

Fig. 4. Vasoconstriction in the presence of protein kinase $A$ inhibitor $\mathrm{H}-89$ obtained after stimulation of femoral artery of control (Wistar) and spontaneously hypertensive rats (SHR) stimulated with $120 \mathrm{mM} \mathrm{KCl}$ and $\mathrm{KCl}+10 \mu \mathrm{M}$ noradrenaline (NA) in Krebs-Henseleit solution (KHS) containing $1.6 \mathrm{mM} \mathrm{Ca}^{2+}(\mathbf{A})$ and in KHS nominally free of $\mathrm{Ca}^{2+}(\mathbf{B}) .{ }^{*} P<0.05 \mathrm{Vs}$. controls, ${ }^{+} P<0.05$ Vs. respective group in the absence of the inhibitor.

different between control Wistar rats and SHR. However, the constriction elicited by $\mathrm{KCl}+\mathrm{NA}$ in $\mathrm{KHS} 0 \mathrm{Ca}^{2+}$ was less pronounced in SHR. A larger inhibition of vasoconstriction of isolated mesenteric arteries after calcium chelation has already been reported by Kahonen et al. (1994) and is in agreement with our previous data reporting greater relaxation after nifedipine in SHR than in controls (Paulis et al. 2007). These results suggest that the activation of intracellular pathways and/or intracellular calcium stores is reduced in SHR. The relative contribution of extracelullar calcium influx to vascular constriction is therefore increased in SHR, which have enhanced activity (Ohya et al. 1998) or higher number (Pratt et al. 2002) of voltage-dependent calcium channels (VDCC). Thus SHR seem to be more dependent on extracellular calcium influx and may require higher level of adrenergic stimulation.

The stimulation by noradrenaline involving the recruitment of $\mathrm{G}_{\mathrm{q}}$ and $\mathrm{G}_{\mathrm{s}}$ proteins leads to activation of protein kinase $\mathrm{C}(\mathrm{PKC})$ and protein kinase $\mathrm{A}$ (PKA), respectively (Nishizuka 1988, Somlyo et al. 1988). In our experiments we aimed to investigate the significance of PKC and PKA in the recruitment of extracellular calcium influx and mobilization of intracellular calcium stores in SHR. Recent studies using inhibitors with improved selectivity for PKC have yielded conflicting results regarding its physiological importance in the vasculature (Chrissobolis et al. 2002, Shirao et al. 2002 McNair et al. 2004). In our experiment, the inhibition of PKC with Ro 31-8220 had no effect on constrictions in SHR, but diminished constrictions in control Wistar rats. Moreover, the constrictions in controls were attenuated in KHS $1.6 \mathrm{Ca}^{2+}$ as well as in KHS $0 \mathrm{Ca}^{2+}$ to similar extent. This fact indicates that in control rats $\mathrm{PKC}$ recruited either by membrane depolarization or by adrenergic stimulation enhances the smooth muscle tone independently on extracellular calcium influx either by modulation of sarcoplasmatic reticulum calcium release (Bonev et al. 1997) or by direct action on myosine (Lamounier-Zepter et al. 2003). These pathways seems to be of less importance in SHR, despite the previously reported higher PKC expression in SHR (Kanashiro et al. 2001).

In contrast to the effect of PKC inhibition, the inhibition of PKA with $\mathrm{H}-89$, a selective and potent inhibitor (Lochner et al. 2006), slightly enhanced constrictions in control rats in both KHS $1.6 \mathrm{Ca}^{2+}$ and KHS $0 \mathrm{Ca}^{2+}$ but reduced them in SHR in KHS $1.6 \mathrm{Ca}^{2+}$. Apparently in control rats the PKA is involved in relaxation. The relaxing effect of PKA in $\mathrm{Ca}^{2+}$-free conditions is supposed to be mediated mainly by inhibition of myosin light chain kinase (Conti and Adelstein 1981). On the other hand, the reduced contraction after PKA inhibition in SHR, observed in our experiment, is more difficult to explain. The mild activation of PKA by lower cAMP concentrations was reported to increase VDCC current in smooth muscle cells and may lead to vasoconstriction (Taguchi et al. 1997, Ruiz-Velasco et al. 1998). In our experiments the effect of PKA on vasoconstriction in SHR was dependent on the presence of extracellular calcium supporting this hypothesis. Moreover, in rat aortic rings pre-incubated with the PKA inhibitor H-89 the albuterol-induced relaxation was attenuated (Ferro et al. 2004).

We conclude that vasoconstriction elicited by adrenergic stimulation is more dependent on extracellular calcium influx in SHR compared to controls. Moreover, the activation of PKA contributes to the vasoconstriction in SHR but not in Wistar. On the other hand, PKC activation seems to play a less 
important role in vasoconstriction in SHR than in Wistar.

\section{Conflict of Interest}

There is no conflict of interest.

\section{Acknowledgements}

Partially supported by the research grant IAA500110902 and by Marie-Curie Intra-European Fellowship COMEin-CARE, PIEF-GA-2009-237834 within the 7th European Community Framework Programme.

\section{References}

ALLEMANY R, VOGLER O, TERES S, EGEA C, BAAMONDE C, BARCELO F, DELGADO C, JAKOBS KH, ESCRIBA PV: Antihypertensive action of 2-hydroxyoleic acid in SHRs via modulation of the protein kinase A pathway and Rho kinase. J Lipid Res 47: 1762-1770, 2006.

BONEV AD, JAGGAR JH, RUBART M, NELSON MT: Activators of protein kinase C decrease $\mathrm{Ca}^{2+}$ spark frequency in smooth muscle cells from cerebral arteries. Am J Physiol 273: C2090-C2095, 1997.

BUDZYN K, PAULL M, MARLEY PD, SOBEY CG: Segmental differences in the roles of rho-kinase and protein kinase $\mathrm{C}$ in mediating vasoconstriction. J Pharmacol Exp Ther 317: 791-796, 2006.

CASTAGNA M, TAKAI Y, KAIBUCHI K, SANO K, KIKKAWA U, NISHIZUKA Y: Direct activation of calciumactivated, phospholipid-dependent protein kinase by tumor-promoting phorbol esters. J Biol Chem 257: 7847 $7851,1982$.

CHRISSOBOLIS S, SOBEY CG: Inhibitory effects of protein kinase C on inwardly rectifying $\mathrm{K}^{+}$and ATP-sensitive $\mathrm{K}^{+}$channel-mediated responses of the basilar artery. Stroke 33: 1692-1697, 2002.

CONTI MA, ADELSTEIN RS: The relationship between calmodulin binding and phosphorylation of smooth muscle myosin kinase by the catalytic subunit of $3^{\prime}: 5^{\prime}$ cAMP-dependent protein kinase. J Biol Chem 256: 3178-3181, 1981.

COX RH: Changes in the expression and function of arterial potassium channels during hypertension. Vascul Pharmacol 38: 13-23, 2002.

FERRO A, COASH M, YAMAMOTO T, ROB J, JI Y, QUEEN L: Nitric oxide-dependent $\beta_{2}$-adrenergic dilatation of rat aorta is mediated through activation of both protein kinase A and Akt. Br J Pharmacol 143: 397-403, 2004.

GOLDBERG MT, TRIGGLE CR: An analysis of the action of lanthanum on aortic tissue from normotensive and spontaneously hypertensive rats. Can J Physiol Pharmacol 55: 1084-1090, 1977.

HERMSMEYER K, ERNE P: Cellular calcium regulation in hypertension. Am J Hypertens 2: 655-658, 1989.

KAHONEN M, ARVOLA P, WU X, PORSTI I: Arterial contractions induced by cumulative addition of calcium in hypertensive and normotensive rats: influence of endothelium. Naunyn-Schmiedeberg's Arch Pharmacol 349: 627-636, 1994.

KANASHIRO CA, KHALIL RA: Gender-related distinctions in protein kinase C activity in rat vascular smooth muscle. Am J Physiol 280: C34-C45, 2001.

KITAZAWA T, ETO M, WOODSOME TP, BRAUTIGAN DL: Agonists trigger G protein-mediated activation of the CPI-17 inhibitor phosphoprotein of myosin light chain phosphatase to enhance vascular smooth muscle contractility. J Biol Chem 275: 9897-9900, 2000.

KO EA, HAN J, JUNG ID, PARK WS: Physiological roles of $\mathrm{K}^{+}$channels in vascular smooth muscle cells. $J$ Smooth Muscle Res 44: 65-81, 2008.

LAMOUNIER-ZEPTER V, EHRHART-BORNSTEIN M, KARCZEWSKI P, HAASE H, BORNSTEIN SR, MORANO I: Human adipocytes attenuate cardiomyocyte contraction: characterization of an adipocyte-derived negative inotropic activity. FASEB J 20: 1653-1659, 2006.

LOCHNER A, MOOLMAN JA: The many faces of H89: a review. Cardiovasc Drug Rev 24: 261-74, 2006.

LOMPRE AM: Sarcoplasmic reticulum in vascular cells in hypertension and during proliferation. Clin Exp Pharmacol Physiol 26: 553-557, 1999.

MARTENS JR, GELBAND CH: Ion channels in vascular smooth muscle: alterations in essential hypertension. Proc Soc Exp Biol Med 218: 192-203, 1998. 
MATSUDA K, LOZINSKAYA I, COX RH: Augmented contributions of voltage-gated $\mathrm{Ca}^{2+}$ channels to contractile responses in spontaneously hypertensive rat mesenteric arteries. Am J Hypertens 10: 1231-1239, 1997.

MCNAIR LL, SALAMANCA DA, KHALIL RA: Endothelin-1 promotes $\mathrm{Ca}^{2+}$ antagonist-insensitive coronary smooth muscle contraction via activation of epsilon-protein kinase C. Hypertension 43: 897-904, 2004.

MIQUEL R, GISBERT R, SERNA E, PEREZ-VIZCAINO F, ANSELMI E, NOGUERA MA, IVORRA MD, D'OCON MP: Acute and chronic captopril, but not prazosin or nifedipine, normalize alterations in adrenergic intracellular $\mathrm{Ca}^{2+}$ handling observed in the mesenteric arterial tree of spontaneously hypertensive rats. J Pharmacol Exp Ther 313: 359-367, 2005.

NISHIMURA J, VAN BREEMEN C: Direct regulation of smooth muscle contractile elements by second messengers. Biochem Biophys Res Commun 163: 929-935, 1989.

NISHIZUKA Y: The molecular heterogeneity of protein kinase $\mathrm{C}$ and its implications for cellular regulation. Nature 334: 661-665, 1988.

OHYA Y, TSUCHIHASHI T, KAGIYAMA S, ABE I, FUJISHIMA M: Single L-type calcium channels in smooth muscle cells from resistance arteries of spontaneously hypertensive rats. Hypertension 31: 1125-1129, 1998.

PAULIS L, LÍŠKOVÁ S, PINTÉROVÁ M, DOBEŠOVÁ Z, KUNEŠ J, ZICHA J: Nifedipine-sensitive noradrenergic vasoconstriction is enhanced in spontaneously hypertensive rats: the influence of chronic captopril treatment. Acta Physiol (Oxf) 191: 255-266, 2007.

PRATT JH, AMBROSIUS WT, AGARWAL R, ECKERT GJ, NEWMAN S: Racial difference in the activity of the amiloride-sensitive epithelial sodium channel. Hypertension 40: 903-908, 2002.

RASMUSSEN H, TAKUWA Y, PARK S: Protein kinase C in the regulation of smooth muscle contraction. FASEB $J$ 1: 177-85, 1987.

RUIZ-VELASCO V, ZHONG J, HUME JR, KEEF KD: Modulation of $\mathrm{Ca}^{2+}$ channels by cyclic nucleotide cross activation of opposing protein kinases in rabbit portal vein. Circ Res 82: 557-565, 1998.

SALAMANCA DA, KHALIL RA: Protein kinase C isoforms as specific targets for modulation of vascular smooth muscle function in hypertension. Biochem Pharmacol 70: 1537-1547, 2005.

SHIRAO S, KASHIWAGI S, SATO M, MIWA S, NAKAO F, KUROKAWA T, TODOROKI-IKEDA N, MOGAMI K, MIZUKAMI Y, KURIYAMA S, HAZE K, SUZUKI M, KOBAYASHI S: Sphingosylphosphorylcholine is a novel messenger for Rho-kinase-mediated $\mathrm{Ca}^{2+}$ sensitization in the bovine cerebral artery: unimportant role for protein kinase C. Circ Res 91: 112-119, 2002.

SOMLYO AP, SOMLYO AV: $\mathrm{Ca}^{2+}$ sensitivity of smooth muscle and nonmuscle myosin II: modulated by G proteins, kinases, and myosin phosphatase. Physiol Rev 83: 1325-1358, 2003.

SOMLYO AP, SOMLYO AV: Signal transduction and regulation in smooth muscle. Nature 372: 231-236, 1994.

SOMLYO AP, WALKER JW, GOLDMAN YE, TRENTHAM DR, KOBAYASHI S, KITAZAWA T, SOMLYO AV: Inositol trisphosphate, calcium and muscle contraction. Philos Trans R Soc Lond B Biol Sci 320: 399-414, 1988.

TAGUCHI K, UEDA M, KUBO T: Effects of cAMP and cGMP on L-type calcium channel currents in rat mesenteric artery cells. Jpn J Pharmacol 74: 179-186, 1997.

TAKUWA Y, RASMUSSEN H: Measurement of cytoplasmic free $\mathrm{Ca}^{2+}$ concentration in rabbit aorta using the photoprotein, aequorin. Effect of atrial natriuretic peptide on agonist-induced $\mathrm{Ca}^{2+}$ signal generation. $J$ Clin Invest 80: 248-257, 1987.

WOOLDRIDGE AA, MACDONALD JA, ERDODI F, MA C, BORMAN MA, HARTSHORNE DJ, HAYSTEAD TA: Smooth muscle phosphatase is regulated in vivo by exclusion of phosphorylation of threonine 696 of MYPT1 by phosphorylation of Serine 695 in response to cyclic nucleotides. J Biol Chem 279: 34496-34504, 2004. 